\title{
Healthy Food Environment
}

National Cancer Institute

\section{Source}

National Cancer Institute. Healthy Food Environment. NCI Thesaurus. Code C92456.

A neig hborhood or locale that provides access to healthy foods and healthy eating alternatives. 